\title{
Dual primary adenocarcinoma of the duodenum and jejunum in a patient with previous colonic cancers
}

\author{
ANDREW C. SWIFT + \\ M.B., Ch.B. \\ G. T. Smith $\dagger$ \\ M.B., Ch.B. \\ D. L. Douglas* \\ F.R.C.S.Ed.
}

\begin{abstract}
Departments of Orthopaedics* and Pathology $\dagger$, University of Sheffield Medical School, Beech Hill Road, Sheffield S10 2RX, and $\ddagger$ Department of Surgery, Frenchay Hospital, Bristol
\end{abstract}

\begin{abstract}
Summary
Primary adenocarcinoma of the small intestine is an uncommon tumour, the incidence being 40-60 times less frequent than carcinoma of the colon. Multiple primary neoplasia of the small bowel, although not infrequently seen with benign growths, is an extremely rare event with malignant lesions. A patient is described who had an adenocarcinoma of the duodenum and jejunum, with a previous history of colonic carcinomas. The case is discussed together with a brief review of the literature.
\end{abstract}

\section{Case report}

A 76-year-old man had presented to his GP on many occasions, over the last few years, with iron deficiency anaemia. This had, until recently, responded well to oral iron, and the cause was therefore not investigated. Over the last 10 months he had developed alternating constipation and diarrhoea and complained of lower abdominal cramp-like pain which he related to exercise. He had lost $6.35 \mathrm{~kg}$ in weight over the last year. His appetite was good, and he did not admit to suffering from dyspepsia, nausea, vomiting, melaena, or bleeding per rectum. He had been feeling tired and weak for the last 8 months, and had recently complained of being short of breath. His doctor had treated him with 20 injections of Imferon ${ }^{\circledR}$ (ferric hydroxide complex) over the month preceding admission.

When 33 years old he had undergone appendicectomy for a perforated appendix; and a right colectomy for carcinoma of the colon was performed 12 years later. He subsequently developed another carcinoma of the colon and had a left colectomy 6 years later. Eleven years after his left colectomy, he presented with an abscess in a left inguinal incision scar. It was thought that his malignant disease had recurred. However, histology did not show any malignant tissue and a barium enema showed no recurrence.

On examination he was found to be grossly anaemic and required urgent admission. His abdomen was soft, there was no visible peristalsis, distension or abnormal mass. The sigmoid colon was tender and palpable, but sigmoidoscopy was normal to $25 \mathrm{~cm}$. On admission the $\mathrm{Hb}$ was $5.4 \mathrm{~g} / \mathrm{dl}$ and the blood film showed a microcytic hypochromic anaemia. A bone marrow showed an active marrow with gross iron deficiency. Serum iron was $1.5 \mu \mathrm{mol} / 1$ (normal 9-32) and total iron binding capacity $42 \mu \mathrm{mol} / 1$ (normal 45-75). He was therefore carefully transfused with 6 units of packed red cells.

A presumptive diagnosis of a recurrence of his colonic carcinoma was made, but a subsequent barium enema showed only a short large bowel and no evidence of carcinoma. However, a barium meal showed a ragged appearance in the first part of the duodenum (Fig. 1). This proved to be significant on endoscopy. The pylorus was spastic and the mucosa oedematous. The duodenum could not be entered but the mucosa seen through the pylorus was thick, red and friable. A gastroscopic biopsy of the duodenal mucosa just distal to the pylorus was taken. Histology showed a poorly differentiated adenocarcinoma with minimal mucin secretion (Fig. 2).

At operation there was a tumour mass arising from the first part of the duodenum involving the local lymph nodes. This was invading the pancreas and extended to the porta hepatis. A second annular tumour was found in the jejunum $30 \mathrm{~cm}$ distal to the duodeno-jejunal flexure. The superior mesenteric lymph nodes were enlarged. The remaining small 
bowel and colon were normal, and the liver appeared free of tumour.

The jejunal tumour was excised together with its mesentery and some of the enlarged lymph nodes, and an end-to-end anastomosis performed. The duodenal lesion was inoperable, but in view of the possibility of future obstruction occurring, an antecolic gastroenterostomy was performed. The jejunal tumour was a well differentiated adenocarcinoma (Fig. 3) arising in the small bowel mucosa and infiltrating through the muscle wall to the serosal surface. The lymph nodes in the mesentery showed reactive changes only.

The immediate postoperative course was uneventful. The patient died at home 5 weeks later. The cause of death was not known and a postmortem was not done.

\section{Discussion}

Carcinoma of the jejunum was first reported by Hamburger, in 1746 (in: Wilson et al., 1974). Since that time there have been many reviews of small bowel neoplasia, but very few recorded cases of multiple small bowel malignancy. Malignant lesions of the small intestine account for $0 \cdot 16 \%$ of all malignancies and $4.9 \%$ of gastrointestinal malignancies (Southam, 1974). Between 30-45\% of these malignancies occur in the duodenum (Shukla and Elias, 1976).

In 1932, Warren and Gates defined certain criteria for classifying multiple malignant tumours as separate primaries. Each tumour must have a definite picture of malignancy, be histologically distinct, and the possibility of one tumour having arisen from a metastasis excluded (Flew, 1972). In this particular case the first 2 criteria are met. However, the possibility that the duodenal tumour

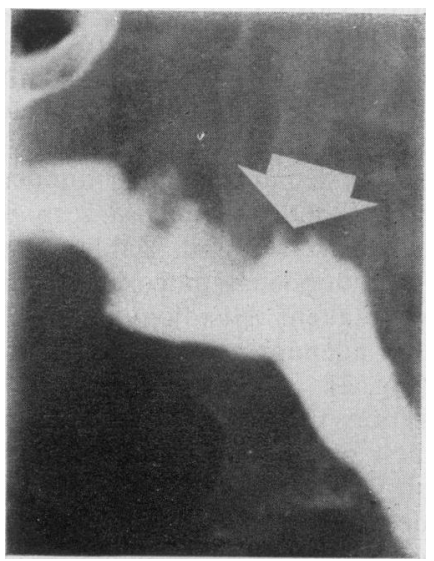

Fig. 1. Barium meal showing a ragged appearance in the first part of the duodenum (arrowed). arose in a metastasis from the jejunal tumour cannot be excluded.

Why such an extensive viscus rarely undergoesc malignant change is not known. Multiple factors $\Rightarrow$ may explain the low incidence, namely the volume of secretion; the fluidity of the contents of the lumen; the lack of stasis; the rapid transit time or the $\frac{\overline{\bar{N}}}{\mathrm{~N}}$ presence of detoxifying enzymes such as benzpyrene $\frac{\bar{\sigma}}{\sigma}$ hydrolase. It may be significant in protecting $\mathscr{\mathbb { }}$ against tumour formation that the small bowel is the most important source of IgA. Immuno-suppressed patients are more likely to develop. tumours, and show increased tendency towards $\vec{\omega}$ developing metastases to the small bowel (Lowenfels, $\frac{\Omega}{\circ}$ 1973). A deficiency in the immunological surveillanceo against tumours might account for the association? of other primary neoplasms with small bowel\% tumours (Wilson et al., 1974). The peak age forg small bowel tumours is between the 5th and 7th? decades.

Adenocarcinoma forms the largest group of small bowel malignancy with an incidence of $\frac{}{5}$ $40-60 \%$. Sarcomas account for $25-35 \%$ and $\vec{\square}$

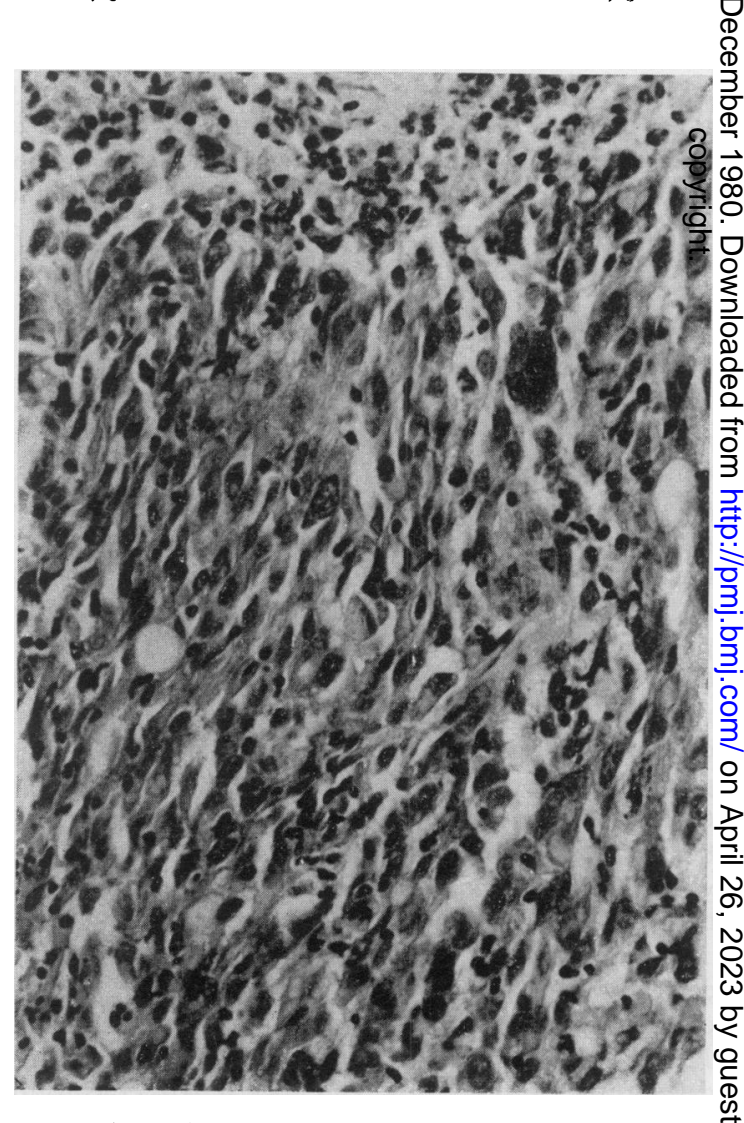

FIG. 2. Photomicrograph of endoscopic biopsy of duodenum showing poorly differentiated adenocarcinoma (HE, $\times 400)$. 
carcinoid tumours for 16-30\% (Goel, Didolkar and Elias, 1976).

Small bowel adenocarcinomas can occur anywhere along the length of the small intestine. Most occur in the duodenum and proximal third of the jejunum; the central third of the ileum is affected very infrequently, and the incidence increases again in the terminal third of the ileum (Lowenfels and Sonni, 1977). For a primary malignant tumour to arise in the duodenal bulb is an extreme rarity.

Macroscopically, the tumour can present in one of 3 forms; a scirrhous annular lesion, an intraluminal polypoid growth or an infiltrating ulcerating lesion. In this case both tumours were of the scirrhous variety, the duodenal lesion being the most likely cause of the chronic blood loss.

Secondaries appear early owing to the relative vascularity and abundant lymphatic drainage. The presence of nodal metastases markedly affects the prognosis, and extra-nodal spread is associated with a very poor prognosis. The depth of invasion

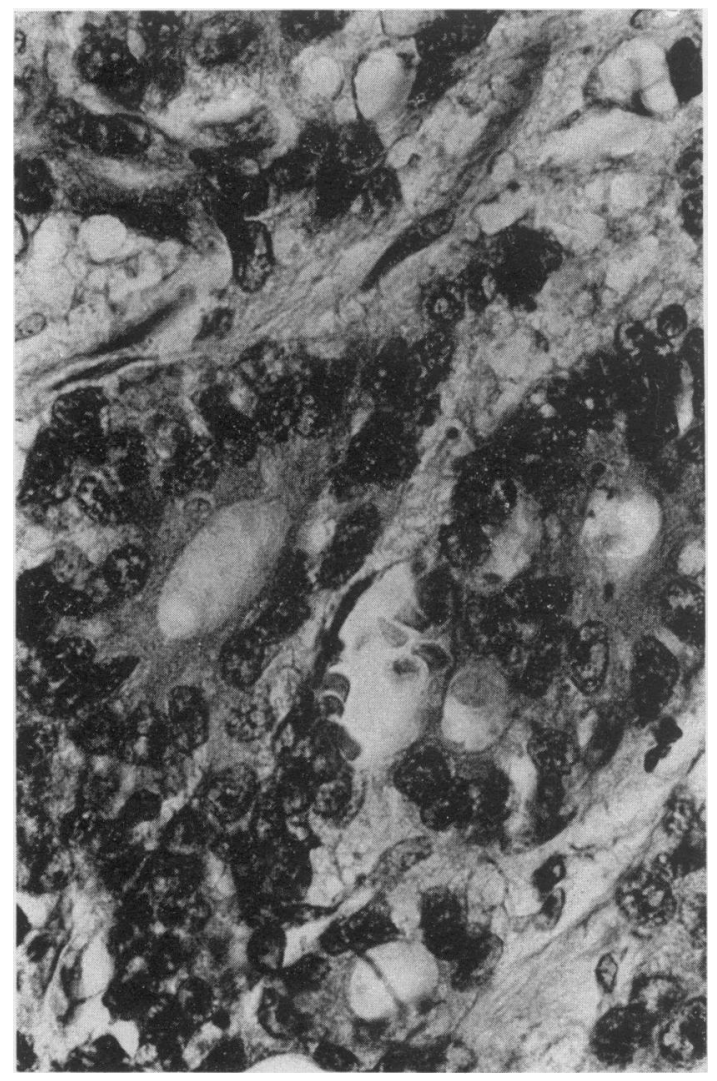

FIG. 3. Photomicrograph of well differentiated adenocarcinoma arising in jejunal mucosa $(\mathrm{HE}, \times 400)$. and tumour size correlate well with the prognosis, but there is little correlation with histological grade (Bridge and Perzin, 1975).

The symptoms are vague and insidious, usually extending over a few months. Recurrent abdominal pain due to chronic intestinal obstruction may occur. Anaemia and weight loss are common presenting features. The symptoms may be so non-specific as to lead to delay in the diagnosis. Occasionally there may be a more dramatic presentation with an intussusception, a perforation or massive haemorrhage. Duodenal neoplasms can present with jaundice, owing to common bile duct obstruction. On examination there may be visible peristalsis or a palpable mass, although the latter is usually a late sign.

Evidence of upper alimentary tract malignancy may be seen on barium meal, but negative findings do not exclude the diagnosis. Upper alimentary endoscopy provides a reliable method for obtaining a definitive diagnosis of growths in the first and second part of the duodenum.

The prognosis is poor with or without treatment. Radical resection offers the only hope of possible cure and improved survival. About $50 \%$ of jejunal and ileal lesions are resectable at laparotomy (Brookes, Waterhouse and Powell, 1968) but radical resection of duodenal lesions is not so easily accomplished. However, palliative resection should be carried out whenever possible. Should resection be impossible, a bypass procedure may make the patient's illness more tolerable.

The average survival time for duodenal growths is significantly worse than for neoplasia elsewhere in the small intestine, being in the order of 2-3 months for unresectable cases (Shukla and Elias, 1976).

The use of radiotherapy and chemotherapy have so far failed to yield any encouraging results (Southam, 1974; Wilson et al., 1974).

Crohn's disease and coeliac disease both predispose to malignant change. In Crohn's disease adenocarcinoma is more common and this arises twice as often in the ileum as the jejunum (Papp and Pollard, 1971; Nesbit et al., 1976).

In coeliac disease, the incidence of both adenocarcinoma and especially lymphoma is greatly increased (Harris et al., 1967) and lymphocytes from patients with coeliac disease show an impaired cytotoxic response to tum our cells from a lymphoma line in vitro suggesting that an impaired immunological surveillance in vivo may account for this increased risk (MacLaurin, Cooke and Ling, 1971).

Carcinoma of the colon is associated with an increased risk of development of another malignancy. Following colectomy and apparent cure of carcinoma of the colon, approximately one-third of the survivors will develop a new malignant lesion 
of either colonic or extra-colonic origin (Polk, Spratt and Butcher, 1965).

It is interesting to note that the present patient developed a second colonic carcinoma 6 years after the initial colonic carcinoma and that both had been successfully treated 29 and 23 years before his present illness.

\section{Acknowledgments}

We wish to thank Mr C. H. Talbot for his kind permission for us to report this case.

\section{References}

Bridge, M. \& Perzin, K.H. (1975) Primary adenocarcinoma of the jejunum and ileum. A clinicio-pathological study. Cancer, 36, 1876.

Brookes, V.S., Waterhouse, J.A.H. \& Powfll, D.J. (1968) Malignant lesions of the small intestine. A ten-year survey. British Journal of Surgery, 55, 405.

FLfW, T.J. (1972) Multiple intestinal malignancies. Proceedings of the Royal Society of Medicine, 65, 753.

Goel, I.P., Didolkar, M.J. \& Elias, E.G. (1976) Primary malignant tumours of the small intestine. Surgery, Gynecology and Obstetrics, 143, 717.

Harris, O.D., CoOKe, W.T., Thompson, H. \& Waterhouse, J.A.H. (1967) Malignancy in adult celiac disease and idiopathic diarrhea. American Journal of Medicine, 42, 899.
Lowenfels, A.B. (1973) Why are small bowel tumours so rare? Lancet, i, 24.

Lowenfels, A.B. \& SonNi, A. (1977) Distribution of small bowel tumours. Cancer Letters, 3, 83.

Maclaurin, B.P., Cooke, W.T. \& LiNG, N.R. (1971) $\overrightarrow{\vec{F}}$ Impaired lymphocyte reactivity against tumour cells in patients with coeliac disease in vitro. Gut, 12, 794.

Nesbit, R.R., Elbadawi, N.A., Morton, J.H. \& Cooper, R.A. (1976) Carcinoma of the small bowel. A complication $\frac{\bar{S}}{7}$ of regional enteritis. Cancer, 37, 2948.

PaPP, J.P. \& Pollard, H.M. (1971) Adenocarcinoma occurring in Crohn's disease of the small intestine. $\infty$ American Journal of Gastroenterology, 56, 149.

Polk, H.C., SpratT, J.S. \& Butcher, H.R. (1965) The frequency of multiple primary malignant neoplasms $\vec{\omega}$ associated with colorectal carcinoma. American Journal of Surgery, 109, 71.

Shukla, S.K. \& Elias, E.G. (1976) Primary neoplasms of 3 the duodenum. Surgery, Gynecology and Obstetrics, 142, if 858.

Southam, J.A. (1974) Primary tumours of the small intestine. के Annals of the Royal College of Surgeons of England, 55, N 129.

WARren, S. \& Gates., O. (1932) Multiple primary malignant tumors. American Journal of Cancer, 16, 1358.

Wilson, J.M., Mebrin, D.B., Gray, G.F. \& Thorbjarn- ARSON, B. (1974) Primary malignancies of the small bowel. A report of 96 cases and review of the literature. Annals of Surgery, 180, 175. 